\title{
Breaking the rule: Five larval instars in the podonomine midge Trichotanypus alaskensis Brundin from Barrow, Alaska
}

\author{
Alec R. LACKMANN, ${ }^{1 *}$ Malcolm G. BUTLER ${ }^{2}$ \\ ${ }^{1}$ North Dakota State University, Department of Biological Sciences, Environmental and Conservation Sciences Program, 1340 Bolley \\ Drive, Fargo; ${ }^{2}$ North Dakota State University, Department of Biological Sciences, Fargo, ND 58102, USA \\ *Corresponding author: alec.lackmann@ndsu.edu
}

\begin{abstract}
Except for one unconfirmed case, chironomid larvae have been reported to pass through four larval instars between egg and pupal stages. We have observed a fifth larval instar to be a standard life-cycle feature of the podonomine Trichotanypus alaskensis Brundin 1966 in tundra ponds on the Arctic Coastal Plain near Barrow, Alaska. T. alaskensis has a one-year life cycle in these arctic ponds. Adults emerge in June $\sim 2-3$ weeks after pond thaw, then mate and oviposit; most newly-hatched larvae reach instar IV by October when pond sediments freeze. Overwintering larvae complete instar IV within a few days of thaw, then molt again to a fifth larval instar. Imaginal discs, normally seen only during instar IV in Chironomidae, develop across both instars IV \& V prior to pupation and adult emergence. While monitoring larval development post-thaw in 2014, we noticed freshly-molted $T$. alaskensis larval exuviae a week or more prior to any pupation by that species. In 2015-16 we reared overwintering instar IV larvae from single pond sources, individually with daily monitoring, through molts to instar V, pupa, and adult. Some overwintering instar II and III larvae were reared as well, but were few in number. During 2016 we also reared T. alaskensis progeny (from eggs) through instar II, thus documenting head capsule size ranges for all five instars in a single pond's population. Without individual rearings, the fifth larval instar was not readily apparent for two reasons: 1) The molt itself occurs immediately after thaw and is so synchronous it is difficult to discern in daily field samples. 2) The head capsule size increment between instars IV-V is much lower than the ratio predicted by the Brooks-Dyar Rule. Up through instar IV, the Brooks-Dyar ratio for T. alaskensis ranged 1.30-1.61, but during the IV-V molt head capsule dimensions (sexes pooled) increased by a ratio of 1.09 - comparable to the magnitude of sexual dimorphism in head capsule size within each of the final two larval instars. Individual rearings coupled with 2014-2016 field surveys in nine other ponds suggest that five larval instars is an obligatory trait of this species at this location. As this is the first confirmed case of five larval instars in a chironomid, the phylogenetic uniqueness of this trait needs further investigation.
\end{abstract}

Key words: Podonominae; Chironomidae; Arctic; Brooks-Dyar rule; larval exuviae.

Received: January 2018. Accepted: April 2018.

This paper was presented at the $20^{\text {th }}$ International Symposium on Chironomidae, Trento, Italy, 2-8 July 2017. Session: Taxonomy and Systematics.

\section{INTRODUCTION}

Chironomids are often the most abundant macroinvertebrates in freshwater, and this ubiquity has strongly encouraged their global study over the past century. The chironomid life-cycle consists of four different stages: the egg, the larval instars, the pupa, and the imago (Armitage et al., 1995), and for decades it is has been a general rule that chironomids pass through four larval instars prior to pupation (Thienemann, 1954; Ford, 1959; Oliver, 1971) based on evidence from the subfamilies Chironominae, Orthocladiinae, Tanypodinae and Diamesinae (McCauley, 1974).

Nevertheless, there have been unconfirmed reports (to date, all except one determined false) of more than four larval instars in the Orthocladiinae (Kettisch, 1937; Styczynski and Rakusa-Suszczwski, 1963). Thienemann (1954) discounted Kettisch's (1937) report of seven larval instars in an orthoclad because the result was not based on individual larval rearings. The report of five larval instars in a tanypod (Sæther, 1968; Oliver, 1971) appears to be misconstrued. The actual source (Styczynski and Rakusa-Suszczwski, 1963) does not mention any tanypodine, but instead documents two orthoclad species with a fifth larval instar group. Their method of determining larval instar groups is poorly described, and is likely inaccurate because they did not individually rear larvae, nor did they account for multiple habitat sources (Usher and Edwards, 1984) or sexual dimorphism (Ford, 1959). Similarly, it was once claimed that the Antarctic midge (Orthocladiinae: Belgica antarctica Jacobs) had six larval instars after larvae were collected from different sources and sorted into instar groups based on head capsule size (Peckham, 1971). The author was aware that habitat-specific size differences could possibly confound the results, but still concluded that the species had six 
larval instars. B. antarctica was later documented to have four larval instars (Sugg et al., 1983; Usher and Edwards, 1984). However, in Chironomus, variable environmental conditions did not lead to significant differences in instar size (Richardi et al. 2013). Thus, there has not been a confirmed report of a chironomid passing through anything other than four larval instars. Here we present evidence of five larval instars in the podonomine midge Trichotanypus alaskensis Brundin based on collections and rearings from a single pond on Alaska's Arctic Coastal Plain (ACP).

\section{METHODS}

The main study site is located near Barrow (Utqiagivik), Alaska $\left(71^{\circ} 17^{\prime} 27.5^{\prime \prime} \mathrm{N} 156^{\circ} 47^{\prime} 18.5^{\prime \prime} \mathrm{W}\right)$ at Pond $\mathrm{OH}$ $\left(71^{\circ} 16^{\prime} 35.4^{\prime \prime} \mathrm{N} 156^{\circ} 38^{\prime} 28.0^{\prime \prime} \mathrm{W}\right)$ approximately $5.5 \mathrm{~km}$ ESE from the village. Pond $\mathrm{OH}$ is a roughly circular, lowcentered polygon pond $(\sim 15 \mathrm{~m}$ in diameter) with a maximum depth of about $35 \mathrm{~cm}$. The emergent sedge Carex aquatilis Wahlenberg surrounds the pond's edge, and in the open water lies flocculent peat-rich sediment with an active layer reaching $\sim 15 \mathrm{~cm}$ maximum, beneath which is permafrost. Like most tundra ponds on the ACP, Pond $\mathrm{OH}$ freezes completely during the winter. In 2015 we reared $T$. alaskensis larvae from $\mathrm{OH}$, while in 2016 we used larvae collected from both Pond $\mathrm{OH}$ and Bear Pond (71¹6’37.1'N 156³8'23.0”W, $50 \mathrm{~m}$ from $\mathrm{OH}$ ).

In addition to Ponds $\mathrm{OH}$ and Bear, we sampled eight other ponds across years 2014-2016 (Icy and Humpback, $130 \mathrm{~m}$ from $\mathrm{OH}$, and Ponds A, C, E, J, G, and Kaleak within $3.1 \mathrm{~km}$ of $\mathrm{OH}$ ). We sampled all ten ponds for $T$. alaskensis larvae, pupae, and emerging adults (by presence of pupal exuviae [PE]) on an every-other-day basis, from pond thaw until emergence. We made collections by sweeping through aquatic vegetation along the edge of ponds with a hand-held dip net, immediately fixing collected specimens in Kahle's fluid (59\% water, $28 \% \mathrm{EtOH}, 11 \%$ formalin, and 2\% glacial acetic acid) (Winterbourn et al., 1989). This fixative highlights pupal/adult primordia (imaginal discs) (e.g. developing legs and wings in the thoracic segments), facilitating accurate analysis of developmental phases (sensu Wülker and Götz, 1968).

Our 2014 observations on T. alaskensis larvae collected in the week following ice-out prompted us to conduct controlled rearings in 2015-2016. Among the 4171 Kahle's-fixed T. alaskensis larvae we collected early in June of 2014, we found numerous specimens preserved in mid-molt, but showing an advanced state of thoracic primordial development. We also found hundreds of fresh larval exuviae (LEs) in these samples, with no pupae present and seemingly no increase in mean larval size relative to earlier samples. We hypothesized that if we were to rear larvae individually immediately after thaw, penultimate and ultimate instar LEs could be collected from each larva.

In both 2015 and 2016 we collected T. alaskensis larvae shortly after pond thaw to rear under semiartificial conditions (Fig. 1) where we could monitor larval and pupal molting. Upon our arrival at the field site on 2 June 2015, much of Pond $\mathrm{OH}$ had already thawed over the prior 1-2 days. We collected $T$. alaskensis larvae from Carex in a part of the pond where much bedfast ice remained. On 26 May 2016, we again collected larvae from the same part of Pond $\mathrm{OH}$, but that year only the pond's periphery had thawed, forming a moat that surrounded solid ice remaining in the pond's center. With most of Bear Pond still frozen on 28 May 2016, we collected T. alaskensis larvae from a newly thawed area of emergent Carex habitat. We suspect that

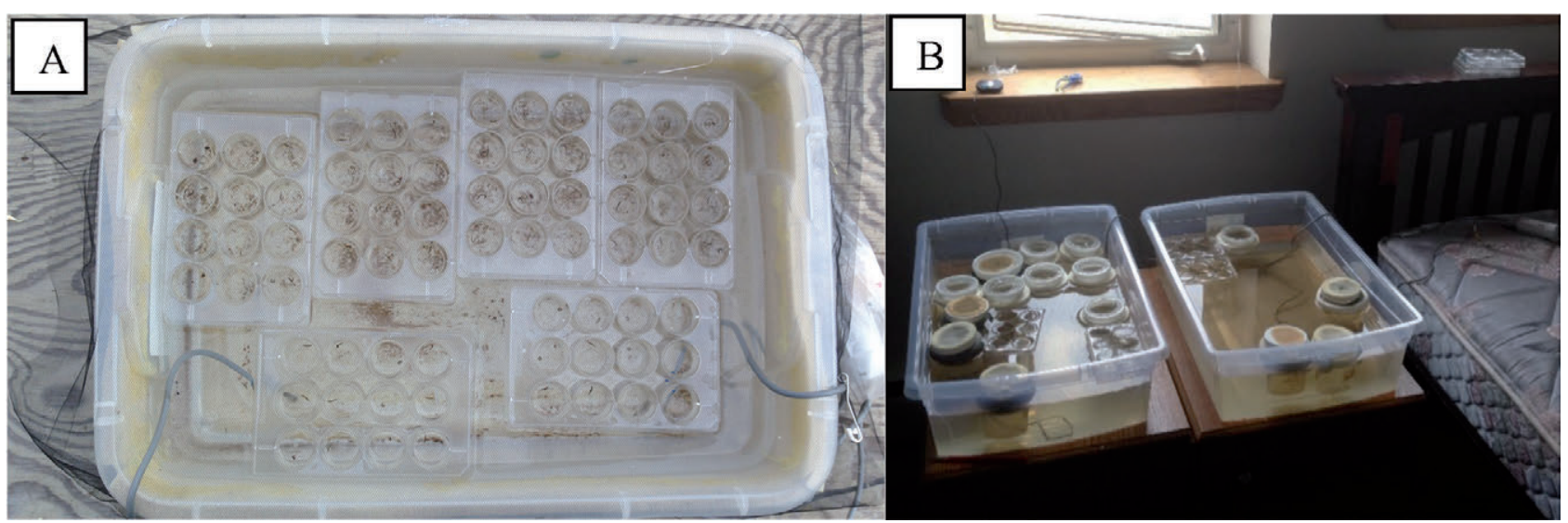

Fig. 1. Rearing setups used in 2015 (A) and 2016 (B). See Methods for details. 
these larvae collected early post-thaw were indicative of the developmental stage at which they overwintered, as Butler and Braegelman (2018) show insignificant growth or development by this species in the first days following thaw.

In 2015, each of $184 T$. alaskensis larvae, freshly collected from Pond $\mathrm{OH}$, was placed in its own well within a 12-well culture plate; these plates were placed in one of two tubs filled with pond water (Fig. 1A), each well receiving about $0.25 \mathrm{ml}$ of detritus slurry via pipette. We placed tubs outdoors near our residence and monitored water temperature using ONSET ${ }^{\circledR}$ HOBOware data loggers, checking rearings at least daily for molting (as indicated by shed LEs). All LEs recovered were preserved individually in vials of $70 \%$ ethanol. We often found a freshly-shed LE along with a teneral larva whose head capsule was still white/translucent, indicating a recent molt. We continued to track larvae for further ecdysis to pupal and adult stages, in which case we collected another LE or PE from that individual.

In 2016, recently-thawed T. alaskensis larvae collected from Pond $\mathrm{OH}$ and Bear Pond were group-reared in buoyant, meshed-sided cups maintained in separate pondspecific tubs, each containing a water-temperature logger (Fig. 1B). We placed approximately 20 larvae, along with detritus as food, into each rearing cup, and maintained the tubs indoors in an unheated room with open windows (Fig. 1B) so the insects experienced near-natural temperature and light conditions. This rearing setup improved on our 2015 method in that it buffered the insects from extreme weather events. We checked all rearing cups two or more times daily for insects undergoing a life-stage change, removing and preserving LEs as they were discovered. We transferred all teneral, white-headed larvae to individual rearing cells within floating six-well plates (Fig. 1B). We tracked subsequent development during the fifth larval instar under two treatments: one with, and one without food. To the "with food" wells we added detritus, adding only settled pond water (pipetted from the clear surface water of the rearing tub) to the "no food" wells. We subsequently tracked these instar V larvae to pupation (collecting their LEs), and then to adult eclosion (collecting PEs). In 2016, we left nine of the initially-collected instar IV larvae in rearing cups to encourage reproduction by emerging adults within a contained area. Emerging adults did produce viable egg masses that we reared individually, and monitored for development several times daily. We preserved (in 70\% ethanol) a subset of the larvulae soon after hatching. Once we observed the first larval molt, we also preserved a subset of instar II larvae, along with their instar I LEs. We preserved surviving larvae, all still in instar II, on 31 July 2016 when we left Barrow.

To discriminate larval instars quantitatively, we took photographs of the shed LEs under an Olympus SZH10 microscope at $70 \mathrm{X}$ magnification using SPOT microscopy imaging software. LEs were placed in 70\% $\mathrm{EtOH}$ in a glass petri dish with a tiny amount of petroleum jelly on the bottom. The jelly works as an adhesive to hold the head capsules in proper orientation (ventral side up) for consistent length and width measurements. This method avoids the compressional forces of mounting head capsules on slides, maintaining the head capsule's threedimensionality. Head capsule length (HCL) and head capsule width (HCW) were measured on LEs that were intact (Fig. 2 A,B). Furthermore, previously preserved larvae from 2014 field samples in Ponds OH, Icy and Humpback were photographed for thoracic imaginal disk primordia (Fig. 2 C,E) to document their developmental stage at the time of molting to the final larval instar.

We analyzed head capsule images with ImageJ software, making linear measurements to the nearest micrometer. We defined HCL as the medial distance from the posterior margin of the gula to the anterior-most point of the mentum, and HCW as the maximum width of the $\mathrm{HC}$ orthogonal to its longitudinal axis (Fig. $2 \mathrm{~A}, \mathrm{~B}$ ). We used JMP 13 Statistical Discovery ${ }^{\mathrm{TM}}$ for statistical analysis and graphical output.

\section{RESULTS}

Our 2015 rearings began with 184 T. alaskensis larvae from Pond OH, 129 of which had large head capsules (presumed instar IV) and 55 were earlier instars (with smaller $\mathrm{HCs}$ and without thoracic primordia). An enormous molting event occurred on 7 June 2015, when we collected all but two of the 116 penultimate (instar IV) LEs from the 129 larger HC larvae (Fig. 3). The other 13 larger larvae either failed in mid-molt to the fifth larval instar (10), escaped (2), or died before molting (1). This evidence strongly suggests the fifth larval instar is obligatory for this species. For those larvae that successfully reached the fifth instar, 49 (42\%) pupated, and the other $58 \%$ failed in their molt to the pupal stadium. Only three pupae eclosed to the adult stage, the rest perished as pupae (Fig. 3A). This low molting success late in the life cycle in 2015 may have resulted from high water temperatures (some over $20^{\circ} \mathrm{C}$ ) and the small rearing wells used that year, relative to our rearings in 2016 (Figs. 1 and 3). Overall, in 2015 we tracked individual growth in HCL for 27 larvae, from the penultimate through the ultimate larval instar (27 of the 105 instar IV data and all instar V data in Fig. 4), excluding LEs with damaged head capsules.

Because we reared individual larvae to pupation or eclosion, we know that the LE measurements shown as instar IV and instar V in Fig. 4 represent penultimate and ultimate instars. Most (78\%) of the 55 larvae in the "small 
HC group" perished before any molt was observed, but we collected 12 additional LEs from larvae that did molt successfully. From HCL measurements, we proposed that four of these larvae had overwintered as instar II, and eight as instar III (shown as triangles for instar II data points, plus all instar III data points in Fig. 4). We later confirmed these instar II and III determinations by rearing F1 progeny of emerging adults in 2016 (see below). None of the 12 instar II or III larvae that did molt to the next instar survived to another molt, possibly due to greater food requirements for these smaller larvae than was available in our small 2015 rearing wells.

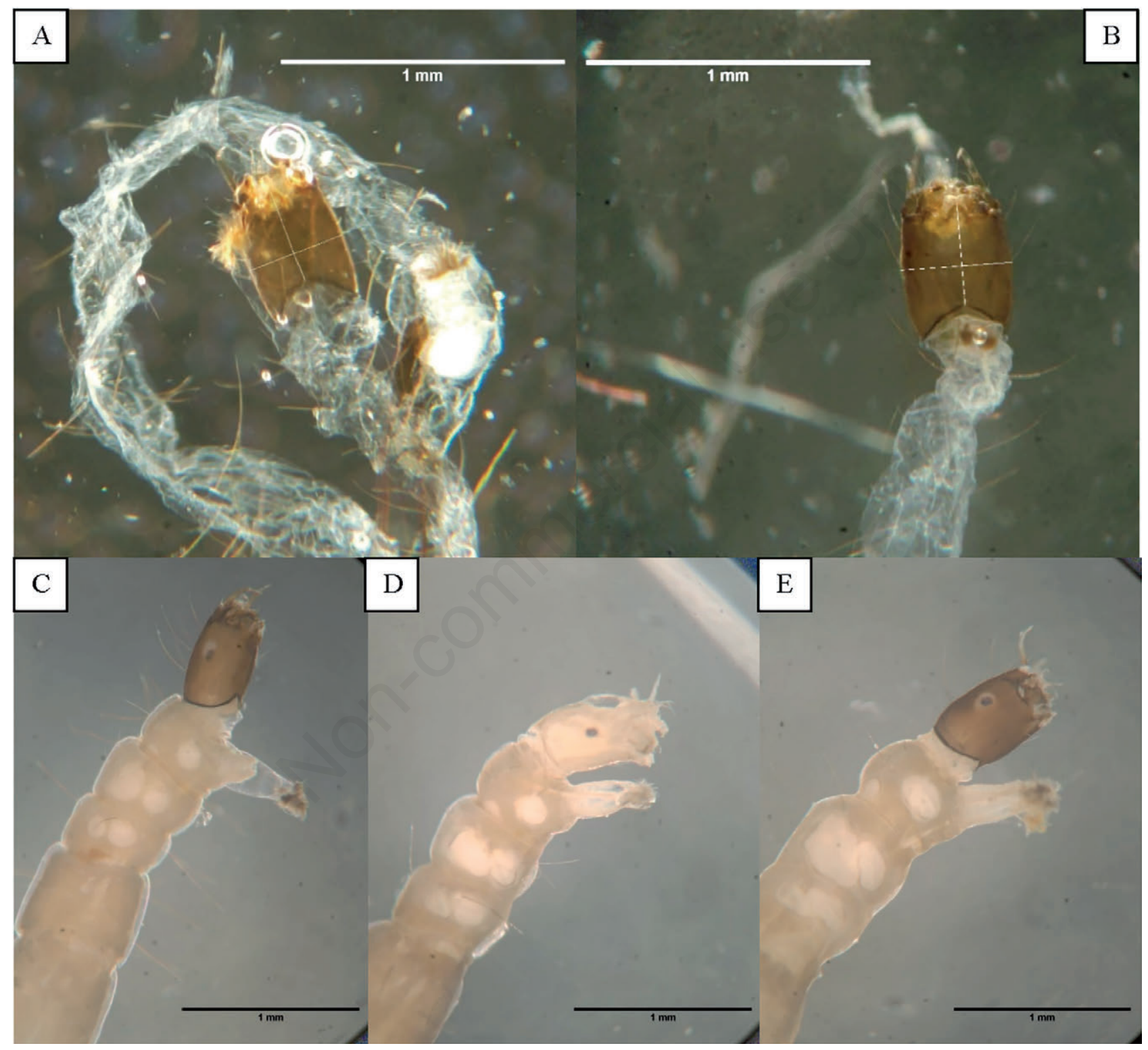

Fig. 2. Fourth (A) and fifth (B) instar larval exuviae from a single T. alaskensis individual. Fine white lines show measurement of head capsule length (HCL) and width (HCW). Here HCL increased by 7.2 and HCW by $9.3 \%$ from larval instar IV to V, more than $20 \%$ less than predicted by the Brook's-Dyar rule, and nearly identical to the magnitude of sexual dimorphism in head capsule size within instars IV and V. C-E) Three female T. alaskensis larvae collected from HB pond on 20 June 2014, and immediately fixed in Kahle's fluid in the field. Relative developmental phase increases from left to right. C) Instar IV nearing ecdysis to larval instar V (note retracting eyespot). D) Teneral instar V larva. Note that at this stage the wing sheath in the second thoracic segment is now confluent with the sheath of the second leg disc. E) Instar V larva at a yet later stage of development as evidenced by enlarged leg, wing, haltere, and respiratory organ primordia. The eyespot is once again centered in its window in the fully-sclerotized head capsule. 
In 2016 we began our Pond OH group rearing with 41 instar IV larvae. One larva died prior to any molt, 34 molted to the fifth instar, and 40 pupated. Thus we deduced that six larvae had already molted to instar $\mathrm{V}$ prior to collection, or that we failed to find their instar IV LEs in the rearing cup. Of the 40 pupae, 33 reached the imago (18 females, 15 males). Most of these adults had been reared in isolation after their molt to instar V (see methods for details), and these adults were preserved immediately upon emergence.

We left some larvae together in the group rearing to encourage reproduction by emerging adults, and on 14 June 2016 we found a male and a female that had emerged together. The female was spent, and we found her egg rope on the bottom of the rearing cup. On 24 June 2016 94 larvulae hatched from these eggs. On 3 July 2016 these larvulae molted to instar II, where they remained until preservation at the end of our field season on 31 July
2016. In addition, two females and one male emerged together on 16 June 2016. One female was spent and we recovered another egg rope which produced 52 larvulae on 25 June 2016. These larvulae also molted on 3 July 2016 and they remained as second instars through the end of our field season. These two egg ropes were reared independently in cups that contained only pond water and detritus (i.e. no other chironomids were present). From these progeny, we measured a total of 26 instar I and 79 instar II T. alaskensis for HCL (Fig. 4).

In 2016 we also group reared 100 instar IV $T$. alaskensis larvae from Bear Pond (Fig. 3C). As we recovered 94 shed penultimate LEs, we again deduced that six larvae had already molted to instar $\mathrm{V}$ prior to collection (or that we missed six LEs in the rearing cups). Eleven larvae died in the final instar, but 89 pupated and we collected their shed instar V LEs. Pupation failure was high (71\%), as only 26 adults eclosed (15 females, 11 males).
A

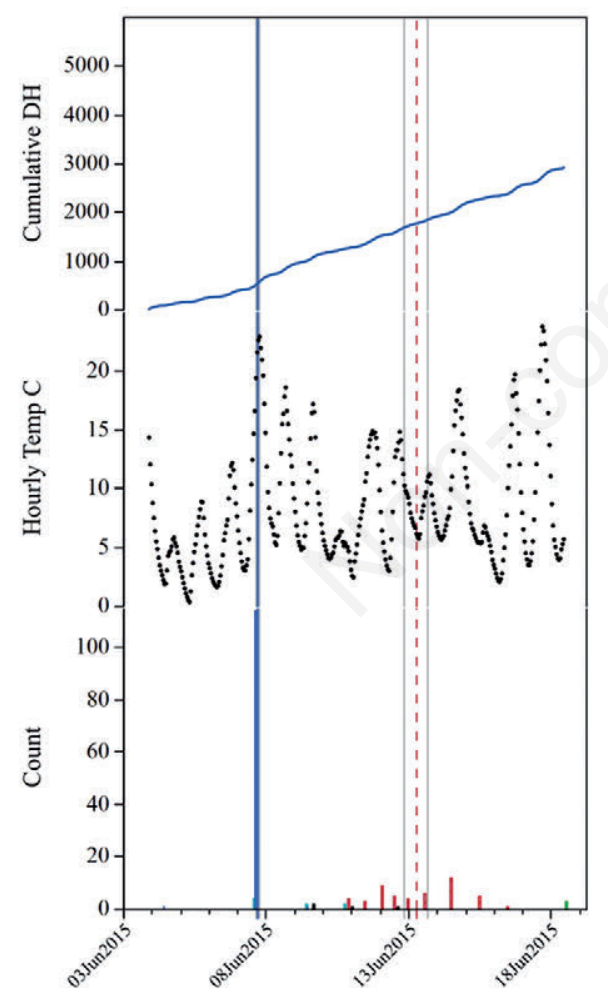

B

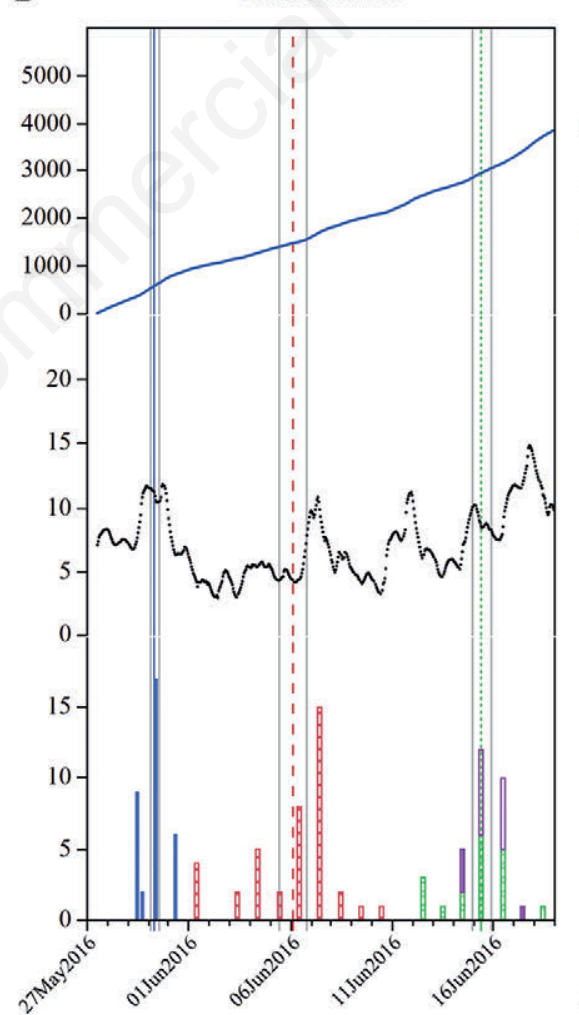

C

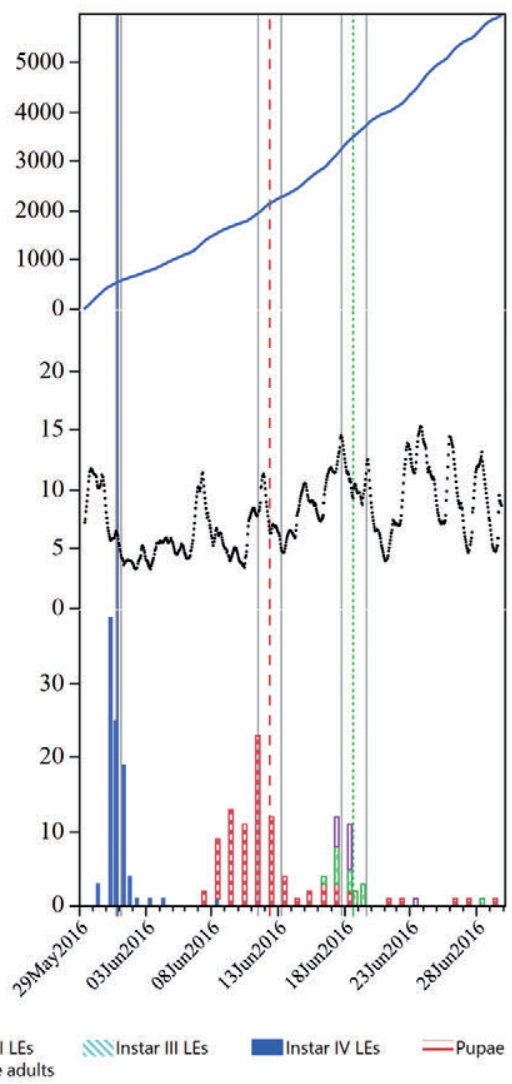

Fig. 3. Summary of T. alaskensis larvae reared in 2015 (A) and 2016 (B-C). Counts are number of individuals molting to instar III (striated black bars), instar IV (teal diagonally-hatched bars), instar V (solid blue bars), pupa (horizontally-hatched bars), and adult ( $q$ green circled bars, $\delta$ purple vertically-hatched bars). Vertical lines show the mean date of ecdysis for the molt to the final larval instar, the pupa, and the imago - with grey lines indicating 95\% CI (adult sexes combined). Hourly temperatures (middle panel) and cumulative degree hours (DH) (upper panel) are plotted. 
Such high pupal mortality (compared to only $17.5 \%$ for the 2016 Pond $\mathrm{OH}$ rearings), likely resulted from use of different trays for rearing individual instar IV larvae and pupae. T. alaskensis collected from Pond $\mathrm{OH}$ molted earlier in June than larvae reared from Bear Pond, and we isolated final-instar larvae from Pond $\mathrm{OH}$ in six-well trays with wells of $19 \mathrm{~mL}$ volume $(3.7 \mathrm{~cm}$ dia x $1.8 \mathrm{~cm})$. These six-well trays were all in use when the Bear Pond rearings escalated, necessitating the use of twelve-well trays with wells of $7.5 \mathrm{ml}$ volume $(2.4 \mathrm{~cm}$ dia $\times 1.7 \mathrm{~cm})$. These smaller wells held $\sim 60 \%$ less water volume with a $58 \%$ reduction in surface area. The water surface in the smaller wells had a prominent meniscus that may have inhibited the pupae's ability to respire and/or emerge successfully. For future work rearing this species, we advise use of wells with a minimum surface area of $10 \mathrm{~cm}^{2}$.

In all rearing experiments, ecdysis to the fifth larval instar was more synchronous than molts to pupation or eclosion. This is evident in the $95 \%$ confidence intervals around mean ecdysis dates for these final three molts (Fig. 3).

Our 2016 rearings indicated that feeding was unnecessary during instar $\mathrm{V}$. Eight of nine instar $\mathrm{V}$ Pond $\mathrm{OH}$ larvae reared with food eclosed as adults (89\%), as did nine of ten such larvae reared without food ( $90 \%$ eclosion). Nine of 43 instar V larvae from Bear Pond reared with food eclosed $(21 \%)$, while eclosion success for larvae reared without food was $18 \%$ ( 8 of 45 emerging as adults). Despite much lower eclosion success among the Bear Pond larvae (discussed above), successful metamorphosis was comparable between treatments. The final (fifth) larval instar in T. alaskensis seems devoted to development, not growth. Nonetheless, Butler and Braegelman (2018) documented larval growth between pond thaw and emergence for T. alaskensis in another Barrow population, and concluded that the species did not meet Danks and

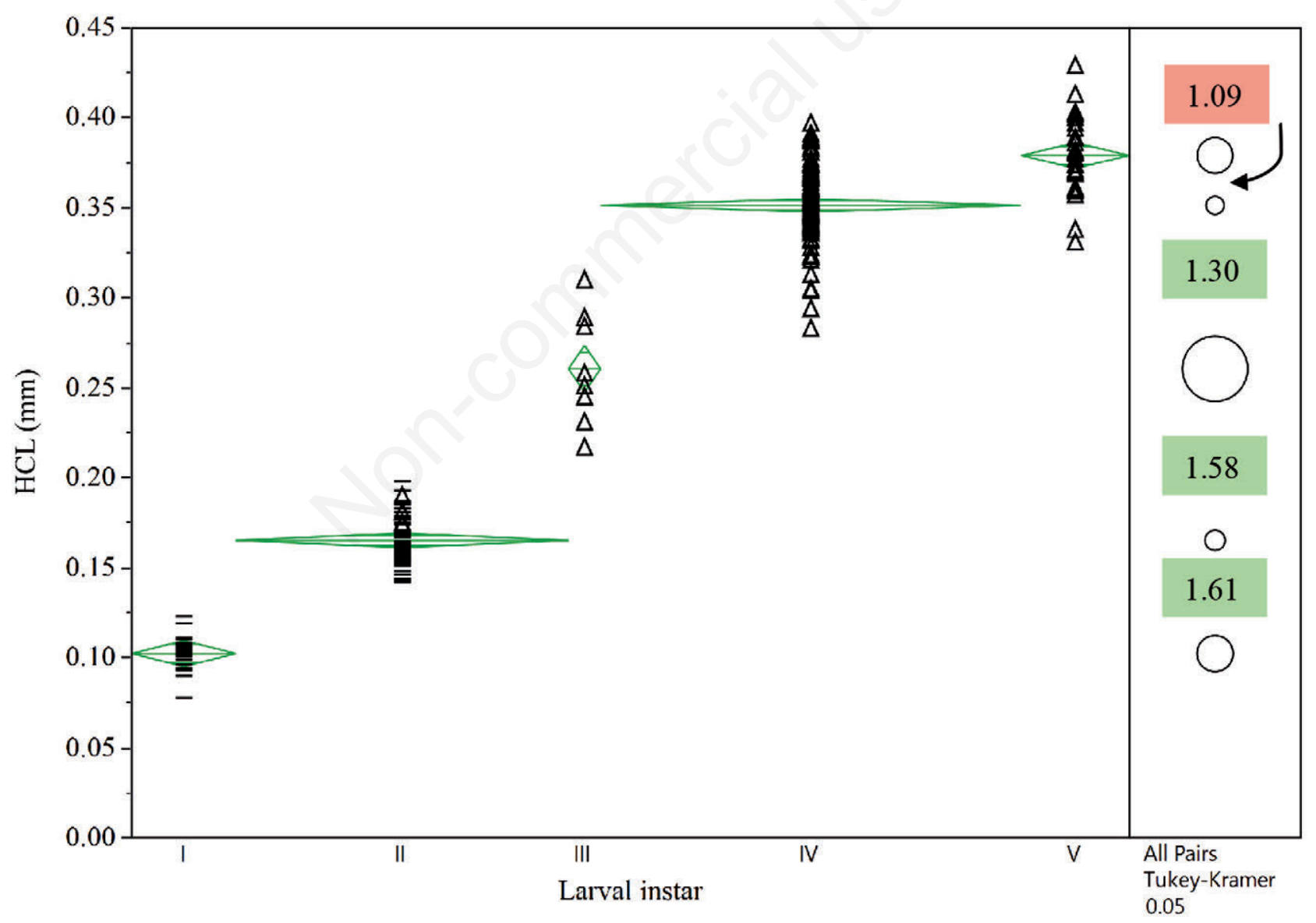

Fig. 4. Head capsule length (HCL) measurements for the five larval instars of T. alaskensis, sexes combined. Open triangles represent data collected in 2015, dashes 2016. Non-overlapping circles on the right represent sizes of $95 \%$ confidence intervals for HCL, illustrating significant statistical differences between instars (all pairs Tukey-Kramer HSD test, alpha=.05). Numbers in green and red boxes show ratios of growth in HCL from one instar to the next. This molting increment follows the Brooks-Dyar Rule through instar IV, but is significantly smaller (1.09) for the molt to instar V. 
Oliver's (1972) criteria for an "absolute spring species". The pre-pupation growth reported by Butler and Braegelman may occur largely during instar IV, and not the final instar.

We found the average increment in HCL during the instar IV-V molt to be only 1.09 , based on measurement of individually-tracked T. alaskensis larvae (Fig. 4). This does not conform to the "Brooks-Dyar Rule" (Brooks, 1886; Dyar, 1890), which holds that linear molt increments in arthropods generally follow a growth ratio of about 1.3-1.7 times their previous size. The Brooks-Dyar Rule may also be used to predict which instars (if any) are missing in a sampled population of arthropods (Crosby, 1973). Our documentation of this small molt increment in head-capsule size between penultimate and final instars indicates that coarse analyses of larval instar distribution in chironomids have potential to underestimate instar count in some taxa. Sexual dimorphism in head capsule dimensions can be significant in the final instar (Ford, 1959; Atchley, 1971), and can potentially confound recognition of instar distinctions if the molt ratio is low.

Comparing the magnitude of $\mathrm{HC}$ size variation due to sex, relative to variation due to instar difference, requires independent determination of both variables. Trichotanypus alaskensis larvae can be sexed easily during both larval instars IV and V because genital primordia are visible in the eighth and ninth abdominal segments, much as in Chironomus (Wülker and Götz, 1968; Ineichen et al. 1983). We also discovered that the molt to instar $\mathrm{V}$ occurs at a consistent stage of thoracic development, about midway through the Wülker and Götz (1968) scheme for final instar Chironomus. Comparing thoracic primordial development of $14\left(5\right.$ 우, $\left.9{ }^{\lambda}\right)$ recently molted instar V larvae (with poorly-sclerotized, white head capsules) to developmental phases of larvae in instar IV and later instar V (with sclerotized HCs), it is evident that this molt occurs when the wing and leg primordia in thoracic segment II become confluent (Fig. 2 C-E). Lack of a sex-specific difference in this developmental event permits one to distinguish instar IV and V larvae based on their developmental stage.
Using thoracic primordial development as an indicator of larval instar, we measured head capsule dimensions of 91 instar IV and 92 instar V Kahle's-preserved $T$. alaskensis collected during June 2014 from Ponds $\mathrm{OH}$ and HB. As larvae from these ponds showed no significant differences in $\mathrm{HC}$ measurements (t-tests), we pooled the data from both ponds.

During larval instar IV, female T. alaskensis HCL and $\mathrm{HCW}$ are $\sim 6-7 \%$ larger than males. During instar V, female head capsules are about 6-8\% larger than males in HCW and HCL (Tab. 1). Between instars IV and V, HCL increases by only $9 \%$ on average (Fig. 4), and HCW by $14 \%$ (data not shown). For T. alaskensis, variation in HC size between and within sexes, coupled with smaller-thanexpected growth increments during the molt to the final larval instar, obscured recognition of a fifth instar by traditional methods.

\section{DISCUSSION}

Our finding of five larval instars in the podonomine midge Trichotanypus alaskensis means we can no longer assume that all chironomids will have four larval instars. We hypothesize that more than four instars may be a plesiomorphic character state within the Chironomidae. This fifth instar appears obligatory in T. alaskensis, at least in the habitat we studied. Potential flexibility of this life history feature could be tested by rearing this species from egg to adult under ideal conditions (e.g. with ad libitum food and without an overwintering diapause). Although five larval instars in Trichotanypus alaskensis may be viewed as an exception to the rule, further study of this and other related taxa may uncover additional surprises.

The synchrony of the molt to instar $\mathrm{V}$ is strong (Fig. 3). How these larvae physiologically regulate such a preciselytimed event is unclear. However, we do know that these larvae molt to the fifth instar at a consistent developmental stage (Fig. 2D) permitting the distinction of instar IV and $\mathrm{V}$ larvae based on thoracic development. Once these larvae

Tab. 1. T. alaskensis sexual dimorphism in HCW and HCL across larval instars IV and V.

\begin{tabular}{|c|c|c|c|c|c|c|}
\hline Instar & Metric & Sex & Mean (mm) & L 95\% & U 95\% & $\mathbf{N}$ \\
\hline IV & Length & $\mathrm{F}$ & 0.378 & 0.366 & 0.389 & 9 \\
\hline IV & Length & M & 0.356 & 0.344 & 0.368 & 8 \\
\hline $\mathrm{V}$ & Length & $\mathrm{F}$ & 0.416 & 0.407 & 0.425 & 13 \\
\hline $\mathrm{V}$ & Length & M & 0.386 & 0.373 & 0.399 & 6 \\
\hline IV & Width & $\mathrm{F}$ & 0.386 & 0.382 & 0.390 & 54 \\
\hline IV & Width & M & 0.361 & 0.356 & 0.365 & 54 \\
\hline $\mathrm{V}$ & Width & $\mathrm{F}$ & 0.449 & 0.443 & 0.454 & 38 \\
\hline $\mathrm{V}$ & Width & M & 0.423 & 0.417 & 0.428 & 37 \\
\hline
\end{tabular}


reach the fifth instar, our evidence suggests they no longer require feeding. Whether or not these larvae may feed during the fifth larval instar in natural conditions remains unknown, but could be tested by monitoring growth (e.g. dry weights) during the fifth larval instar.

Trichotanypus alaskensis deviates from the BrooksDyar rule in the last of its four larval molts, with a growth ratio so small that individual variation and sexual size dimorphism can easily confound distinction of the final two instars. Why Trichotanypus alaskensis has an "extra" larval instar is open to speculation. Head capsule shape in this species is quite cylindrical, relative to the more taperedspherical head capsules typical of larvae in the Tanypodinae, Orthocladiinae, and Chironominae. Yet the apparent lack of growth in the brief final instar of $T$. alaskensis confounds arguments based on shape/volume considerations. Perhaps more plausible than any "adaptive" scenario is the possibility that this fifth larval instar is a phylogenetic legacy from an ancient time when instar number was not as rigidly constrained as we have heretofore believed. Much remains up to speculation as to why $T$. alaskensis has an extra larval instar.

\section{CONCLUSIONS}

In his discussion of nematoceran phylogeny, Edwards (1926) broadly stated that the Chironomidae seemed to have reduced the number of larval instars to four. Once additional evidence had accumulated from the Chironominae and Orthocladiinae, Thienemann (1954) hypothesized that four larval instars likely would be found universally within the Family Chironomidae. Ford (1959) then tested Thienemann's prediction by studying instar numbers of six species within the Orthocladiinae, Tanypodinae, and Diamesinae. For all these species Ford found four larval instars, noting sexual dimorphism in $\mathrm{HC}$ dimensions within the final larval instar. He concluded that all the freshwater chironomid subfamilies conformed to Thienemann's generalization of four larval instars in the Chironomidae - although the Podonominae was not tested. McCauley (1974) studied 29 species across the Tanypodinae, Orthocladiinae, and Chironominae, finding all to have four larval instars based on HC sizes. Our discovery of five larval instars in the Podonominae, a phylogenetically basal subfamily (Cranston et al., 2012) breaks Thienemann's rule. Further life-history analysis of other basal taxa could improve our understanding of both chironomid and nematoceran evolution.

\section{ACKNOWLEDGMENTS}

This work was completed at North Dakota State University (NDSU), USA as part of a doctoral dissertation by
ARL. The North Slope Borough and the Ukpeagvik Inupiat Corporation permitted access to the field site. We thank Ewelina Bielak-Lackmann, Daniel C. McEwen, and Kevin M. Cortes for assistance in the field and lab, and Shane D. Braegelman for helpful discussion and advice. We gratefully acknowledge financial support from the U.S. Arctic Landscape Conservation Cooperative, the U.S. National Fish and Wildlife Foundation, and the Environmental and Conservation Sciences Program at NDSU.

\section{REFERENCES}

Armitage P, Cranston PS, Pinder LCV, 1995. The Chironomidae: The biology and ecology of non-biting midges. 1. Chapman and Hall, London: 572 pp.

Atchley W, 1971. Components of sexual dimorphism in Chironomus larvae (Diptera: Chironomidae). Am. Nat. 105:455-466.

Brooks WK, 1886. Report on the Stomatopoda collected by HMS Challenger during the years 1873-1876. Zoology. $1116 \mathrm{pp}$.

Butler, MG, 1980. Emergence phenologies of some arctic Alaskan Chironomidae, p. 307 314. In: D.A. Murray (ed.), Chironomidae: ecology, systematics, cytology, and physiology. Pergamon Press.

Butler MG, Braegelman SD, 2018. Pre-emergence growth and development in the arctic midge Trichotanypus alaskensis Brundin. J. Limnol. 77(s1):1836. DOI: 10.4081/jlimnol. 2018.1836.

Cranston PS, Hardy NB, Morse GE, 2012. A dated molecular phylogeny for the Chironomidae (Diptera). Syst. Entomol. 37:172-188.

Crosby TK, 1973. Dyar's Rule predated by Brooks' Rule. New Zeal. Entomol. 5:175-176.

Danks HV, Oliver DR, 1972. Seasonal emergence of some high arctic Chironomidae (Diptera). Can. Entomol. 104:661-686.

Dyar HG, 1890. The number of molts of lepidopterous larvae. Psyche 5:420-422.

Edwards FW, 1926. The phylogeny of nematocerous Diptera: a critical review of some recent suggestions. Proceedings of the 3rd International Congress on Entomology, Zurich 2:111-130.

Ford JB, 1959. A study of larval growth, the number of instars and sexual differentiation in the Chironomidae (Diptera). Physiol. Entomol. 34:151-160.

Ineichen H, Meyer B, Lezzi M, 1983. Determination of the developmental stage of living fourth instar larvae of Chironomus tentans. Develop. Biol. 98:278-286.

Kettisch J, 1937. [Zur Kenntnis der Morphologie und Oekologie der Larve von Cricotopus trifasciatus].[Article in German]. Z. syst. Insekt. 15:153-165.

McCauley VJ, 1974. Instar differentiation in larval Chironomidae (Diptera). Can. Entomol. 106:179-200.

Oliver DR, 1971. Life history of the Chironomidae. Ann. Rev. Entomol. 16:211-230.

Peckham V, 1971. Notes on the chironomid midge Belgica antarctica Jacobs at Anvers Island in the maritime Antarctic. Pac Insects Monogr. 25:145-166. 
Richardi VS, Rebechi D, Aranha JM, Navarro-Silva MA, 2013. Determination of larval instars in Chironomus sancticaroli (Diptera: Chironomidae) using novel head capsule structures. Zoologia (Curitiba) 30:211-216.

Sæther OA, 1968. Chironomids of Finse Area Norway with special reference to their distribution in a glacier brook. Arch. Hydrobiol. 64:426-483.

Styczynski B, Rakusa-Susczczewski S, 1963. Tendipedidae of selected water habitats, of Hornsund region (Spitzbergen). Polskie Arch. Hydrobiol. 2:327-341.

Sugg P, Edwards JS, Baust J, 1983. Phenology and life history of Belgica antarctica, an Antarctic midge (Diptera: Chironomidae). Ecol. Entomol. 8:105-113.
Thienemann A, 1954. Chironomus. Leben, Verbreitung und wirtschaftliche Bedeutung der Chironomiden. Schweizerbart, Stuttgart: $834 \mathrm{pp}$.

Usher MB, Edwards M, 1984. A dipteran from south of the Antarctic Circle: Belgica antarctica (Chironomidae) with a description of its larva. Biol. J. Linn. Soc. 23:19-31.

Winterbourn MJ, Gregson KL, Dolphin CH, 1989. Guide to the aquatic insects of New Zealand. Entomological Society of New Zealand, Auckland: 80 pp.

Wülker W, Götz P, 1968. [Die Verwendung der Imaginalscheiben zur Bestimmung des Entwicklungszustandes von Chironomus-Larven (Dipt.)].[Article inGerman]. Zoomorphology 62:363-388. 